\title{
Mother Tongue Word Order Competence and Second Language Writing Skills: A Case Study of Acoli and English
}

\author{
Akello Lucy Dora
}

This paper reports the findings of a study that delved into the relationship between mother tongue $\left(L_{1}\right)$ word order competence and second language $\left(L_{2}\right)$ writing skills, taking the case of Acoli and English respectively. It reports that, triggered by concerns that schools that instruct their pupils in $L_{1}$ before introducing $L_{2}$ perform worse than those that use $L_{2}$ from the start, the study involved the administration of a test of $L_{1}$ word order competence and $L_{2}$ writing skills to 177 pupils of primary four, selected from Gulu District of Uganda. Using the Pearson Product Moment Correlation test, the scores on $L_{1}$ word order competence were correlated with those on $L_{2}$ writing skills. The findings were that there is a significant relationship between the variables $(r=.813, p .=.000)$. Therefore, it is recommended that the Ministry of Education and Sports, as well as other stakeholders, promote the adoption of $L_{1}$ as a medium of instruction in the early grades.

Key words: Medium of Instruction; Language Education; Mother Tongue; Acoli

\section{Introduction}

Through providing the main medium of communicating meaning, language plays an important role in learning. Thus, it is essential that learners are taught in a language that they properly understand and speak. Often, people understand, and speak, their first language $\left(\mathrm{L}_{1}\right)$, usually their mother tongue (UNESCO, 2005), best. Indeed, a compelling body of literature (including Okech, 2001; UNESCO, 2005; Veloso, 2003; Crystal, 1987) contends that, on account of this, there is a direct relationship between $\mathrm{L}_{1}$ competence (i.e. knowledge possessed by native users of a language that enables them to speak to and understand others (Finch, 2000)) and competence in other areas of learning. For example, Veloso (2003) argues that $\mathrm{L}_{1}$ is the best language in which to learn how to read and write, adding that skills in that language facilitate the acquisition of similar skills in another language $\left(\mathrm{L}_{2}\right)$. This has given credence to the "first-language-first" model of medium of instruction, which argues that learners should be instructed in their $\mathrm{L}_{1}$ before the introduction of foreign languages as media of instruction; and motivated the adoption of learners' $L_{1}$ as a medium of instruction, especially in the early grades of the primary education cycle. In China, for example, many indigenous languages are used at various levels of education (in some cases up to the university level); in Uganda, government requires primary schools to adopt their pupils' local area languages (i.e. $\mathrm{L}_{1}$ ) as the medium of instruction in the first four years of the primary education cycle (RoU, 1992); and in Nepal, the government made a constitutional provision to allow for the delivery of primary education in the learners' $L_{1}$ as the medium of instruction on top of

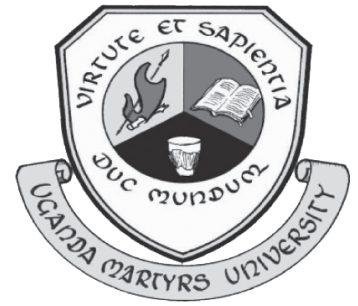

Journal of Science and Sustainable Development Copyright (C) 2009 Uganda Martyrs University ISSN: 2070-1748; Vol 2 (1): 47-49 www.umu.ac.ug 
developing text books in several minority languages to facilitate the implementation of this provision (Kosonen, 2005). Among others, South Africa, Kenya and Tanzania present similar examples.

For a number of reasons, however, many education systems do not realize their aspiration to offer their learners instruction in their $\mathrm{L}_{1}$. In China, for example, most ethno-linguistic minorities are taught in Chinese (Kosonen, 2005), notwithstanding the country's commitment to the use of indigenous languages in instruction. Similar examples are found in Malaysia, where mother tongue-based bilingual education is provided only in major languages (e.g. Mandarin, Chinese and Tamil); Brunei, the Philippines and Singapore, among others. Incidentally, for learners from linguistic minorities, proficiency in relevant national language(s) is essential, to enable them to communicate beyond their immediate community and secure opportunities for further education and employment. Notwithstanding the benefits associated with the "first-language-first" model of medium of instruction, therefore, many learners are taught in $\mathrm{L}_{2}$. This creates dualistic systems, in which both $\mathrm{L}_{1}$ and $\mathrm{L}_{2}$ are used.

Uganda typifies this dualism. English, a foreign language, is the medium of instruction for mainstream schools. In some instances, however, schools follow the "first-language-first" model, teaching their pupils in their $\mathrm{L}_{1}$ up to grade four (ages 9 to 10) before introducing English as a medium of instruction, just as is urged by RoU (1992). Contrary to the propositions of the model, however, the schools that use $\mathrm{L}_{2}$ from the start perform better than those that start with $\mathrm{L}_{1}$ (Okech, 1999). On top of bringing the credibility of the model to question, this has also raised concerns, with critics arguing that instruction in $\mathrm{L}_{1}$ is inversely related to competence in other areas of learning upon the introduction of $\mathrm{L}_{2}$ as a medium of instruction. Notwithstanding the (relatively) poor performance of schools that use $\mathrm{L}_{1}$ as a medium of instruction in the first years of the primary education cycle, hitherto, there was no evidence linking this performance to instruction in $\mathrm{L}_{1}$ in particular. Taking the case of Acoli $\left(\mathrm{L}_{1}\right)$ word order competence and English $\left(\mathrm{L}_{2}\right)$ writing skills, therefore, this study delved into the plausibility of these concerns. The findings were that there is a significant positive relationship between $\mathrm{L}_{1}$ word order competence and $\mathrm{L}_{2}$ writing skills, which vindicates the "first-language-first" model. It is, therefore, recommended that government, and other stakeholders, promote the adoption of the propositions of the model.

\section{Method}

The study was carried out in Gulu District, one of the most cosmopolitan districts of Uganda in which Acoli is widely spoken as a native language. Data were collected from 177 pupils of primary four (P4), using a semi-structured performance test on $\mathrm{L}_{1}$ (Acoli) word order competence and $\mathrm{L}_{2}$ (English) writing skills. The pupils were drawn from schools in four counties of the District. They had all been taught in $\mathrm{L}_{1}$ for the first three years of their primary education (i.e. primary one to primary three) after which English was introduced as the medium of instruction. The test included two sections, namely, $\mathrm{L}_{1}$ Word Order Competence and $\mathrm{L}_{2}$ Writing Skills. $\mathrm{L}_{1}$ Word Order Competence examined the pupils' grasp of the rules governing the combination of words into phrases, clauses and sentences; while $\mathrm{L}_{2}$ Writing Skills examined their graphical skills (i.e. writing graphemes, spelling, punctuation, capitalization and format), because they are the element of $\mathrm{L}_{2}$ that the learners are expected to have covered in $\mathrm{P} 4$. The pupils' responses to the test were examined by their teachers of the respective languages after which the scores obtained, which were expressed in percentages, were entered, into an SPSS file, by the two sections of the test. To establish the relationship between $\mathrm{L}_{1}$ Word Order Competence and $\mathrm{L}_{2}$ Writing Skills, the scores on the two sections were correlated in a Pearson Product Moment Correlation test, at the level of confidence alpha $=.05$. 


\section{Findings and Discussion}

Pearson Product Moment Correlation coefficient for the relationship between $\mathrm{L}_{1}$ Word Order Competence and $\mathrm{L}_{2}$ Writing Skills was established at .813, with a corresponding asymptotic sig. of .000. This means that there is a strong, and statistically significant, relationship between the two variables, given the correlation coefficient established and the fact that the asymptotic sig. established (i.e. .000) is less than the predetermined level of sig. (i.e. .05). This relationship is direct, meaning that pupils that were better at $\mathrm{L}_{1}$ Word Order were also better at $\mathrm{L}_{2}$ Writing Skills. Thus, the study validates the view that learners that start their education in their $\mathrm{L}_{1}$ grasp other learning experiences better than those that start their instruction in $\mathrm{L}_{2}$, which is in concurrence with the conclusions of earlier researchers on the subject (e.g. Okech, 2001; UNESCO, 2005; Veloso, 2003; Crystal, 1987; Nation, 2001). Through indicating that the better the pupils' $\mathrm{L}_{1}$ word order competence the better their $\mathrm{L}_{2}$ writing skills competence, the study indicates that the performance differentials between schools that start their instruction in $\mathrm{L}_{1}$ and those that start it in $\mathrm{L}_{2}$ cannot be attributed to the fact that the schools that perform poorer start their instruction in $\mathrm{L}_{1}$. Rather, the study leads to the conclusion that the performance differential between schools that start their instruction in $\mathrm{L}_{1}$ and those that start it in $\mathrm{L}_{2}$, in disfavour of the former are due to other factors, meaning that the latter would perform even better if they started instructing their learners' in their $\mathrm{L}_{1}$ first. To this end, it is recommended that the Ministry of Education and Sports, as well as other stakeholders, promote the adoption of $\mathrm{L}_{1}$ as a medium of instruction in the early grades. This could be done through explaining to the critics of the "first-language-first" model that its propositions have been tested by this, among other studies.

\section{References}

Crystal, D., 1987. The Cambridge encyclopaedia of language. New York: Cambridge university press.

Finch, G., 2000. Linguistic terms and concepts. London: Macmillan press limited.

Kosonen, K., 2005. Education in indigenous languages: policy andpractice in South-East Asia. Thailand: UNESCO Asia and Pacific regional bureau for Education.

Nation, I. S. P., 2001. Learning vocabulary in another language. Oxford: Oxford university press.

Okech, A., 1999. Multilingual literacy as a resource. Kampala: UPPC.

RoU, 1992. Education for National Integration and Development: Government white paper on the recommendation of the report of the Education Policy Review Commission. Entebbe: UPPC.

UNESCO, 2005. First language first: community-based literacy programmes for minority language contexts in Asia. Bangkok: UNESCO.

Veloso, T., 2003. Indigenous languages in education. Translated by Heloísa Modesto, 2003. Pangolim, March 2003, (4).

\section{ABOUT THE AUTHOR}

AKELLO LUCY DORA is a lecturer at the Faculty of Education, Uganda Martyrs University. For correspondence please contact her at: P. O. BOX 5498, Kampala, Uganda.

E-mail: lakello@umu.ac.ug 
